\title{
Granulation Effectiveness of Iron Ore Sinter Feeds: Effect of Ore Properties
}

\author{
Congcong YANG, ${ }^{1)}$ Deqing ZHU, ${ }^{1 / *}$ Jian PAN ${ }^{11}$ and Liming $\mathrm{LU}^{2)}$ \\ 1) School of Minerals Processing and Bioengineering, Central South University, Changsha, 410083 China. \\ 2) CSIRO Mineral Resources, Kenmore, QLD 4069, Australia.
}

(Received on March 5, 2018; accepted on April 23, 2018; J-STAGE Advance published date: June 23, 2018)

\begin{abstract}
This paper developed a quantitative understanding of the effect of ore properties on granulation effectiveness for different iron ore types based on the mechanistic model proposed by J.D. Litster et al. The granulation effectiveness was measured by the magnitude of $x_{0.5}$, which was postulated to be a function of the layer binding strength. Water was adopted as the only binder for all granulation tests. A wide range of moisture contents, up to the optimum moisture content that yielded an optimum permeability, was tested for each ore type. The typical structure of granules made from different ores was investigated to reveal the effect of mineralogical properties of ore particles on the growth of granules. The results indicate that the granulation effectiveness $x_{0.5}$ varies markedly with ore type and moisture content. Feed particle size distribution and moisture for granulation are paramount factors determining the granulation effectiveness $x_{0.5}$, which has a single relationship with the mass mean size of layering particles independent of ore type. The mass mean size of layering particles is dependent on the inherent size distribution of raw materials and the mass fraction of layering particles, while the latter is linear to available moisture content. The model works well for some ore types except for those with unreasonable size distributions: 1) excessive intermediate particles meanwhile lacking of fine particles; or 2) excessive ultrafine particles. An effective criteria closely related to layer binding strength, $(1-\varepsilon) S / \varepsilon \bar{d}$, is proposed to determine the applicability of the model.
\end{abstract}

KEY WORDS: granulation effectiveness; model; iron ore; particle; size distribution.

\section{Introduction}

Granulation of sinter feeds is an indispensable step in the iron ore sintering process. Through granulating, iron ore fines, fluxes, fuels and recycle materials (e.g., return fines, dust, etc.) are made into granules that possess appropriate moisture, reasonable size distribution and good bed permeability for sintering. The granulation behavior of a particular ore mix determines the structure and chemistry of the granules, and these will subsequently influence the local sintering reactions that take place. ${ }^{1)}$ Therefore, understanding the granulation behavior of sinter feeds is extremely important as a window to offer a better insight into how the granulation of particles proceeds, what main factor affects the granulation efficiency of sinter feeds, what strategy can be proposed for optimizing the granulation effectiveness of sinter mix, etc.

Fundamentally, the granulation of sinter feeds is a particle size enlargement process implemented by the layering of adhering fine particles onto the coarser nucleus particles. ${ }^{2,3)}$ This process generally proceeds under the action of water, and in many circumstances with a specific binder (typi-

\footnotetext{
* Corresponding author: E-mail: dqzhu@csu.edu.cn

DOI: http://dx.doi.org/10.2355/isijinternational.ISIJINT-2018-141
}

cally hydrated lime) which can significantly improve the granulation efficiency by increasing granule strength and deformability. ${ }^{4-6)}$ When the process conditions for example the granulation time, space factor and the binder addition are fixed, the inherent physicochemical and mineralogical properties of iron ores are believed to be the dominant factor affecting the granulation effectiveness and the properties of the adhering layer of granules. ${ }^{7,8)}$ The effect of ore characteristics on the granulation effectiveness has so far been investigated by many researchers. ${ }^{8-13)}$ Reportedly, the granulation effectiveness was influenced by a series of ore properties such as particle size distribution, particle shape and surface characteristics, porosity and water-holding capacity, etc., all of which seemed to be independent with each other. Recently, the fractal parameter was introduced for interpretation of granulation process. ${ }^{14)}$ Nevertheless, from a quantitative view, ${ }^{11)}$ the moisture available for granulation (total moisture less the moisture absorbed by feed materials) and the size distribution of raw materials are the paramount factors, whereas other ore properties such as particle shape and surface characteristics are of secondary importance because these properties actually take effect through their impact on the moisture absorption capability. ${ }^{15)}$ These experiments in J.D. Litster et al.'s work ${ }^{11)}$ were initially conducted on a range of simplified mixtures of iron ores and low moisture 
level of not exceeding $5.4 w t \%,{ }^{16)}$ and currently there is no developed quantitative understanding of the effect of ore properties on the granulation effectiveness of single ores yet. Extending the quantitative understanding of granulation process from a simplified mixture to single ores has huge potential in evaluation and prediction of the granulation effectiveness of singe ores, and moreover providing reliable strategy for ore blending.

In this work, an attempt was made to quantitatively interpret the effect of ore properties on the granulation effectiveness of iron ores, which was defined as cutoff size $x_{0.5}$ equivalent to the particle size when partition coefficient was 0.5 based on the mechanistic model of the granulation process proposed by J.D. Litster et al. ${ }^{11)}$ Compared with other models, this model is simpler and more realistic for mechanistic understanding of the factors affecting the granulation effectiveness, encouraging its application to industrial situations. ${ }^{16)}$ A group of mainstream iron ore fines possessing different mineralogical properties and particle size distributions were tested.

\section{Mechanistic Model Proposed by J.D. Litster et al.}

According to an earlier study, ${ }^{17)}$ the iron ore particles act either as nuclei particles or adhering particles in the granulation process. A partition coefficient $\alpha_{i}$ was defined to present the mass fraction of particles from size fraction $i$ which act as nuclei particles, and can be calculated from the experimental data. ${ }^{11}$

$$
\alpha_{\mathrm{i}}=\frac{m_{i i}+m_{i i+1}}{\sum_{j=i}^{n} m_{i j}}
$$

where $m_{i j}$ represents the mass of particles of size fraction $i$ which are found in granules of size fraction $j$. Values of $\alpha_{i}$ is between 0 and 1 , corresponding to totally adhering particles and totally nuclei particles, respectively, while $x_{0.5}$ is the cutoff size at which half of the particles act as nuclei particles and half act as adhering particles. Then, $x_{0.5}$ is hypothesized to be a function of the layer binding strength, which is dominated by the capillary forces:

$$
x_{0.5}=f\left(\sigma_{T}\right)=f\left(\frac{1-\varepsilon}{\varepsilon} \frac{S}{d}\right) .
$$

where $\sigma_{\mathrm{T}}$ is the tensile strength of the wet granule, $S$ is the fractional saturation of the voids in the adhering layer, $\varepsilon$ is the porosity of the adhering layer, $d$ is the size of the layering particles.

The liquid saturation of the layer $S$ can be calculated by:

$$
S=\frac{1-\varepsilon}{\varepsilon} \frac{W_{g}}{\rho_{H_{2} O} V_{p}}
$$

where $W_{\mathrm{g}}$ is the water available for the granulation, $\mathrm{kg} / \mathrm{m}^{3}$ of dry iron ore, and $V_{\mathrm{p}}$ is the total volume fraction of layering particles. The total volume fraction of layering particles $V_{\mathrm{p}}$ can be calculated from the experimental data of partition coefficient $\alpha_{i}$ and the particle size distribution of iron ores by:

$$
V_{p}=\sum_{i=1}^{n}\left[\left(1-\alpha_{i}\right) \frac{w_{i}}{\rho_{a}}\right] /\left(1 / \rho_{a}\right)=\sum_{i=1}^{n}\left[\left(1-\alpha_{i}\right) \cdot w_{i}\right] \ldots \ldots .
$$

where $w_{i}$ is the mass fraction of ore particles in size distribution $i$, and $\rho_{\mathrm{a}}$ represents the apparent density of iron ore.

In addition, the water available for the granulation $W_{\mathrm{g}}$ equals to the value of the total moisture added in the drum $W_{\mathrm{T}}$ less the moisture absorbed by the feed materials $W_{\mathrm{a}}$.

$$
W_{g}=W_{T}-W_{a} .
$$

In the earlier work, ${ }^{11)}$ the calculations of the moisture absorbed by the feed materials did not consider the difference of the water absorption capacity between the nucleus and layering particles. Moreover, the dividing size of the nucleus and layering particles was simply fixed at $0.25 \mathrm{~mm}$, which actually varied remarkably with the partition coefficient $\alpha_{i}$.

Therefore, this work also presents our contributions to the calculation of the moisture available for granulation in the model: 1) the consideration of the difference of the water absorption capacity between the nucleus and adhering particles; 2) the role of particles act is closely related to the partition coefficient at a specific moisture content, which determines the actual mass fraction of adhering particles. Hence, the moisture absorbed by iron ores was calculated as the sum of moisture absorbed by nucleus particles $W_{a-N}$ and that absorbed by adhering particles $W_{a-A}$ :

$$
W_{a}=W_{a-N}+W_{a-A}
$$

And the $W_{a-N}$ and $W_{a-A}$ are calculated by:

$$
W_{a-N}=M_{a-N} \sum_{i=1}^{n}\left(\alpha_{i} w_{i}\right) /\left(1 / \rho_{a}\right)=M_{a-N} \rho_{a}\left(1-V_{p}\right) \ldots \ldots . .(7)
$$

$$
W_{a-A}=M_{\mathrm{a}-A} \sum_{i=1}^{n}\left[\left(1-\alpha_{i}\right) \cdot w_{i}\right] /\left(1 / \rho_{a}\right)=M_{a-A} \rho_{a} V_{p}
$$

where $M_{a-N}$ and $M_{a-A}(\mathrm{~kg}$ water $/ \mathrm{kg}$ dry mass) are the moisture absorbed by particles which act as nucleus particles and adhering particles, respectively.

Then, Eq. (5) becomes:

$$
W_{g}=W_{T}-\left[M_{a-N} \rho_{a}\left(1-V_{p}\right)+M_{a-A} \rho_{a} V_{p}\right]
$$

\section{Materials and Methods}

\subsection{Materials Characterization}

Five types of iron ores were adopted in this work, i.e., three Australian iron ores (AO-P, AO-F, AO-Y) and two Brazilian iron ores (BO-C, BO-T), all of which were widely used in the sintering plants. Table 1 gives their representa-

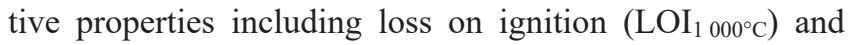
major mineral phases, apparent density, porosity and moisture absorption capacity of nucleus and adhering particles. Typically, particles with a $-5,+3 \mathrm{~mm}$ size distribution were used to measure the apparent density, porosity and moisture absorption capacity of nucleus particles in accordance to the experimental procedure provided by J.D. Litster et $a l .{ }^{11)}$ Meanwhile, the moisture absorption capacity of adhering particles was determined by the molecular water 
Table 1. Properties of raw materials.

\begin{tabular}{|c|c|c|c|c|c|c|}
\hline \multirow{2}{*}{ Ores } & \multirow{2}{*}{$\begin{array}{l}\mathrm{LOI}_{1000^{\circ} \mathrm{C}} \\
\quad(w t \%)\end{array}$} & \multirow{2}{*}{ Major mineral phases } & \multirow{2}{*}{$\begin{array}{l}\text { Apparent density } \rho_{\mathrm{a}} \\
\left(\mathrm{kg} / \mathrm{m}^{3}\right)\end{array}$} & \multirow{2}{*}{$\begin{array}{l}\text { Porosity of ore } \\
\text { particles }^{\mathrm{a}} \\
(\%)\end{array}$} & \multicolumn{2}{|c|}{ Moisture absorption capacity $(\mathrm{kg} / \mathrm{kg}$ dry ore $) \times 10^{3}$} \\
\hline & & & & & Nucleus particles ${ }^{\mathrm{a}}, \mathrm{M}_{a-N}$ & Adhering particles ${ }^{\mathrm{b}}, \mathrm{M}_{a-A}$ \\
\hline AO-P & 6.44 & Goethite, hematite & 3067 & 25.6 & 56.01 & 67.29 \\
\hline AO-F & 7.42 & Goethite, hematite & 3309 & 18.5 & 38.38 & 54.76 \\
\hline AO-Y & 12.01 & Goethite & 2824 & 20.9 & 51.16 & 51.34 \\
\hline BO-C & 2.55 & Hematite & 3591 & 17.2 & 29.46 & 44.75 \\
\hline BO-T & 1.97 & Specular hematite & 3596 & 14.7 & 22.52 & 31.57 \\
\hline
\end{tabular}

a : $-5+3 \mathrm{~mm}$ ore particles; ${ }^{\mathrm{b}}$ : $-0.5 \mathrm{~mm}$ ore particles.

Table 2. Mass fraction of raw materials in each size range $(\mathrm{mm})$.

\begin{tabular}{|c|c|c|c|c|c|c|c|c|c|c|c|c|c|}
\hline \multirow{2}{*}{ Ores } & \multirow{2}{*}{+10} & \multirow{2}{*}{$-10+8$} & \multirow{2}{*}{$-8+6.3$} & \multirow{2}{*}{$-6.3+5$} & \multirow{2}{*}{$-5+3$} & \multirow{2}{*}{$-3+2$} & \multirow{2}{*}{$-2+1$} & \multirow{2}{*}{$-1+0.5$} & \multicolumn{5}{|c|}{-0.5} \\
\hline & & & & & & & & & $-0.5+0.25$ & $-0.25+0.125$ & $-0.125+0.063$ & -0.063 & Sub-total \\
\hline AO-P & 0.60 & 5.11 & 7.49 & 9.36 & 15.60 & 7.07 & 10.86 & 13.70 & 9.11 & 3.38 & 3.56 & 14.16 & 30.21 \\
\hline $\mathrm{AO}-\mathrm{F}$ & 2.01 & 7.86 & 8.88 & 8.88 & 16.41 & 4.93 & 17.08 & 9.52 & 8.81 & 2.60 & 3.86 & 9.16 & 24.43 \\
\hline $\mathrm{AO}-\mathrm{Y}$ & 10.86 & 18.04 & 9.75 & 7.30 & 11.34 & 4.30 & 9.29 & 8.74 & 7.29 & 2.73 & 2.41 & 7.95 & 20.38 \\
\hline $\mathrm{BO}-\mathrm{C}$ & 5.49 & 6.00 & 6.39 & 7.38 & 12.18 & 4.53 & 6.53 & 9.91 & 15.45 & 8.18 & 4.60 & 13.36 & 41.59 \\
\hline BO-T & 2.07 & 3.68 & 4.12 & 4.64 & 9.64 & 4.50 & 9.95 & 6.03 & 8.06 & 7.27 & 12.51 & 27.53 & 55.37 \\
\hline
\end{tabular}

content test developed by Qiu et al. ${ }^{18)}$ using the particles less than $0.5 \mathrm{~mm}$ with a soaking time of $5 \mathrm{~min}$. Three replicates were carried out for each sample. AO-P and AO-F are Marra-Mamba ores but the former is highly porous with a porosity of $25.6 \%$ while the latter is relatively dense with a porosity of $18.5 \%$. AO-Y is a Pisolite ore with a low density

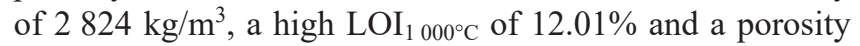
of $20.9 \%$. Compared with Australian iron ores, BO-C and $\mathrm{BO}-\mathrm{T}$ are hematite ores with lower $\mathrm{LOI}_{1} 000^{\circ} \mathrm{C}$ and particle porosity. However, BO-T is a typical specular hematite ore with a relatively low porosity of $14.7 \%$. The moisture absorption capacity of nucleus and adhering particles is found to exhibit a positive relationship with their porosity, which is believed to be closely related to mineralogical characteristics of iron ores.

Given the particle size distributions of raw materials in Table 2, it is easy to know that particle size of iron ores varies widely with ore type. AO-Y is relatively coarse with only $20.38 w t \%$ particles less than $0.5 \mathrm{~mm}$, whereas BO-T is relatively fine with $55.37 w t \%$ particles less than $0.5 \mathrm{~mm}$, and nearly half of which is less than $0.063 \mathrm{~mm}$. Higher load of ore particles close to the $0.1 \mathrm{~mm}$ size range is more likely to reduce permeability and increase granulating moisture. ${ }^{10)}$ The amounts of ore particles less than $0.5 \mathrm{~mm}$ in AO-P, AO-F and BO-C are $30.21 w t \%, 24.43 w t \%$ and $41.59 w t \%$, respectively.

\subsection{Methods}

To stabilize the operation of granulation tests, each raw material was screened into several fractions, i.e., $+8,-8+6.3,-6.3+5,-5+3,-3+1$ and $-1 \mathrm{~mm}$ using the wet sieving procedure recommended in ISO standard 4701-1999. All attached fines and dust removed from larger particles during the wet sieving process were collected into $-1 \mathrm{~mm}$ fraction. The wet-screened materials in each size fraction were subsequently dried at $105^{\circ} \mathrm{C}$ for more than
$12 \mathrm{~h}$. For determination of size distribution of iron ores as given in Table 2, approximately $1 \mathrm{~kg}$ material in each size fraction plus $1 \mathrm{~mm}$ was further dry-screened into more size fractions while $0.5 \mathrm{~kg}$ material less than $1 \mathrm{~mm}$ applied a wet sieving method.

Granulating experiments of single ores were performed in a typical granulation drum of $390 \mathrm{~mm}$ diameter and $175 \mathrm{~mm}$ length. The drum contained eight lifter bars of $5 \mathrm{~mm}$ height. The rotary speed of drum was set to $20 \mathrm{rpm}$ corresponding to a Froude number of 0.0044 similar to an industrial granulation drum in sintering plant. Each ore for granulation was made up of different size fractions in accordance to its original size distribution, and its total mass was determined from its density and a fixed space factor of $12 \%$ in the drum. The iron ore was pre-mixed for $2 \mathrm{~min}$, and subsequently a measured mass of water was added to the ore particles over 1 min using a spray nozzle. The granulation was allowed to undergo for a further $5 \mathrm{~min}$. When it came to the end of granulation, the granulated material was immediately removed from the drum and transferred to a rotary sample divider where an approximately $0.6 \mathrm{~kg}$ sample was taken for moisture measurement, a $0.75 \mathrm{~kg}$ sample for frozen size analysis using liquid nitrogen, ${ }^{19)}$ and the rest for packed bed permeability measurement. Frozen size analysis of granulated material was carried out using a series of squarehole sieves from $0.25 \mathrm{~mm}$ to $10 \mathrm{~mm}$, while the packed bed permeability was measured in JPU (Japanese Permeability Units $^{20)}$ ) through a cylindrical permeability pot of $100 \mathrm{~mm}$ diameter and $200 \mathrm{~mm}$ height. Each granule size fraction obtained from frozen sizing was dried at $105^{\circ} \mathrm{C}$ for more than $12 \mathrm{~h}$ and then weighed. The dried granules in each size fraction were first soaked in water for a while to allow de-agglomeration and then wet-screened at $0.063,0.125$ and $0.25 \mathrm{~mm}$ successively followed by dry sieving of the plus $0.25 \mathrm{~mm}$ materials. While the size distributions of granules and particles in each granule size fraction were obtained, 
the partition coefficient $\alpha_{i}$ could be calculated from Eq. (1). A wide range of granulation moistures was tested from low moisture levels to high moisture levels at which optimum permeability occurred. Generally, the appropriate operating mix moisture was found to be $80 \%$ to $90 \%$ of the optimum moisture content that yields an optimum pre-ignition permeability. ${ }^{21)}$ Therefore, further size analysis of each granule size fraction obtained from the frozen sizing step was only applied to the granulated materials containing moistures below the optimum moisture content where the optimum permeability was achieved.

According to the J.D. Litster et al.'s model, ${ }^{11)}$ the porosity of the adhering layer is an important parameter to reveal the relationships between the granulation effectiveness and layer properties. In this work, the layer porosity was estimated from the measurement of the dry bulk density of a particle bed (using $-0.5 \mathrm{~mm}$ fraction) packed in a cylinder mold of $11 \mathrm{~mm}$ diameter after being pressed under a constant load of $100 \mathrm{~N}$ for $5 \mathrm{~min}$. Duplicate tests were conducted for each iron ore. It was assumed that the layer porosity was independent of size distribution of adhering particles and therefore would not change with the granulation moisture. A parallel measurement of the porosity of the particle packed bed (using $-1 \mathrm{~mm}$ fraction) also confirmed that the porosity of the adhering layers made up with $-0.5 \mathrm{~mm}$ and $-1 \mathrm{~mm}$ materials was quite similar with a neglectable difference of $\pm 0.5 \%$.

In addition, an observation of the typical structure of granules made from different iron ores at similar $x_{0.5}$ was performed using a Leica DMLP optical microscope. Thus, the effect of mineralogical properties of nucleus and adhering particles on their granulation effectiveness could be revealed.

\section{Results and Discussion}

\subsection{Packed Bed Permeability of Granulated Materials}

Figure 1 shows the packed bed permeability of granulated materials with varying moistures for different ore types. While these ores show similar trend of packed bed permeability with the granulation moisture, each ore has its

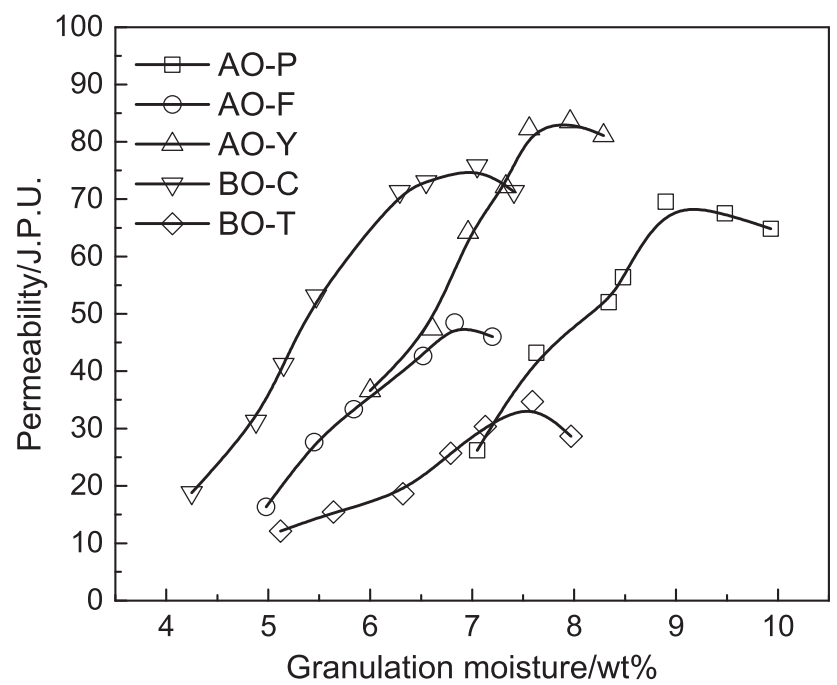

Fig. 1. Packed bed permeability vs. granulation moisture curves for different ores. distinct optimum permeability at its own specific moisture content. Furthermore, the magnitude of optimum permeability varies widely with the ore type in sequence: $\mathrm{AO}-\mathrm{Y}>$ $\mathrm{BO}-\mathrm{C}>\mathrm{AO}-\mathrm{P}>\mathrm{AO}-\mathrm{F}>\mathrm{BO}-\mathrm{T}$, while optimum moisture contents follow the sequence: $\mathrm{AO}-\mathrm{P}>\mathrm{AO}-\mathrm{Y} \approx \mathrm{BO}-\mathrm{T}>$ $\mathrm{AO}-\mathrm{F} \approx \mathrm{BO}-\mathrm{C}$.

It was concluded by various researchers ${ }^{8,21-23)}$ that the optimum permeability was heavily dependent on the bed voidage and mean granule size. The latter was the main factor determining the permeability of granulated materials. Obviously, mean granule size was largely affected by the inherent size distribution of feed material and the amount of water added in the granulation, which further influenced the amount of layering particles and thickness of the adhering layer. Larger granules with lower layer thickness generally resulted in higher permeability. Related to the water absorption capacity and the size distributions of raw materials in Tables 1 and 2, it is believed that the granulation effectiveness of ore particles at specific moisture content plays an important role in the size enlargement of granules. For example, AO-F is relatively coarse and possesses a much lower level of $-0.5 \mathrm{~mm}$ fraction than BO-C, but it shows evidently inferior permeability throughout the moisture range.

\subsection{Granulation Effectiveness of Single Ores with Varying Moisture Content}

Figure 2 shows the variation in partition coefficient with particle size for different ores. The values of $x_{0.5}$ for five ore types were directly read off the Fig. 2 and then plotted in Fig. 3 against the granulation moisture.

For a particular ore, the value of $x_{0.5}$ increases with the moisture content and higher value of $x_{0.5}$ means larger mean granule size. While five ores show similar trend of $x_{0.5}$ with granulation moisture contents, the moisture required to reach a specific value of $x_{0.5}$ varies greatly from ore to ore. Furthermore, in comparison to the $x_{0.5}$-moisture curves of AO-P, AO-Y and BO-C, the curves of AO-F and BO-T turn out to be lower and flatter, indicating a slower increase of layering particle size with moisture content and poorer granulation effectiveness. The maximum values of $x_{0.5}$ for five ore types follow the sequence: BO-C (1.54 at $6.29 w t \%$ moisture) $>$ AO-P (1.40 at $8.90 w t \%$ moisture) $>\mathrm{AO}-\mathrm{Y}$ (1.10 at $7.56 w t \%$ moisture) $>\mathrm{AO}-\mathrm{F}(0.66$ at $6.83 w t \%$ moisture $)>$ BO-T $(0.53$ at $7.13 w t \%$ moisture $)$. The relative magnitude of maximum $x_{0.5}$ for different ores, to some extent, can reflect the packed bed permeability is good or bad, as shown in Fig. 1. The inconsistency between the optimum permeability of AO-P and $\mathrm{BO}-\mathrm{C}$ and their values of $x_{0.5}$ compared to that of $\mathrm{AO}-\mathrm{Y}$, from one aspect, further reveals the effect of granule properties (e.g., granule size, layer thickness) on packed bed permeability.

\subsection{Factors Affecting the Granulation Effectiveness}

According to J.D. Litster et al., ${ }^{11)}$ the granulation effectiveness of a simplified ore mixture was a complex function of the feed particle size and available moisture for granulation. Different from an ore blend presenting more the integrated effect of ore mixture properties, granulation of a single iron ore presents larger effect of its distinct ore property. From this point, more factors need to be taken 

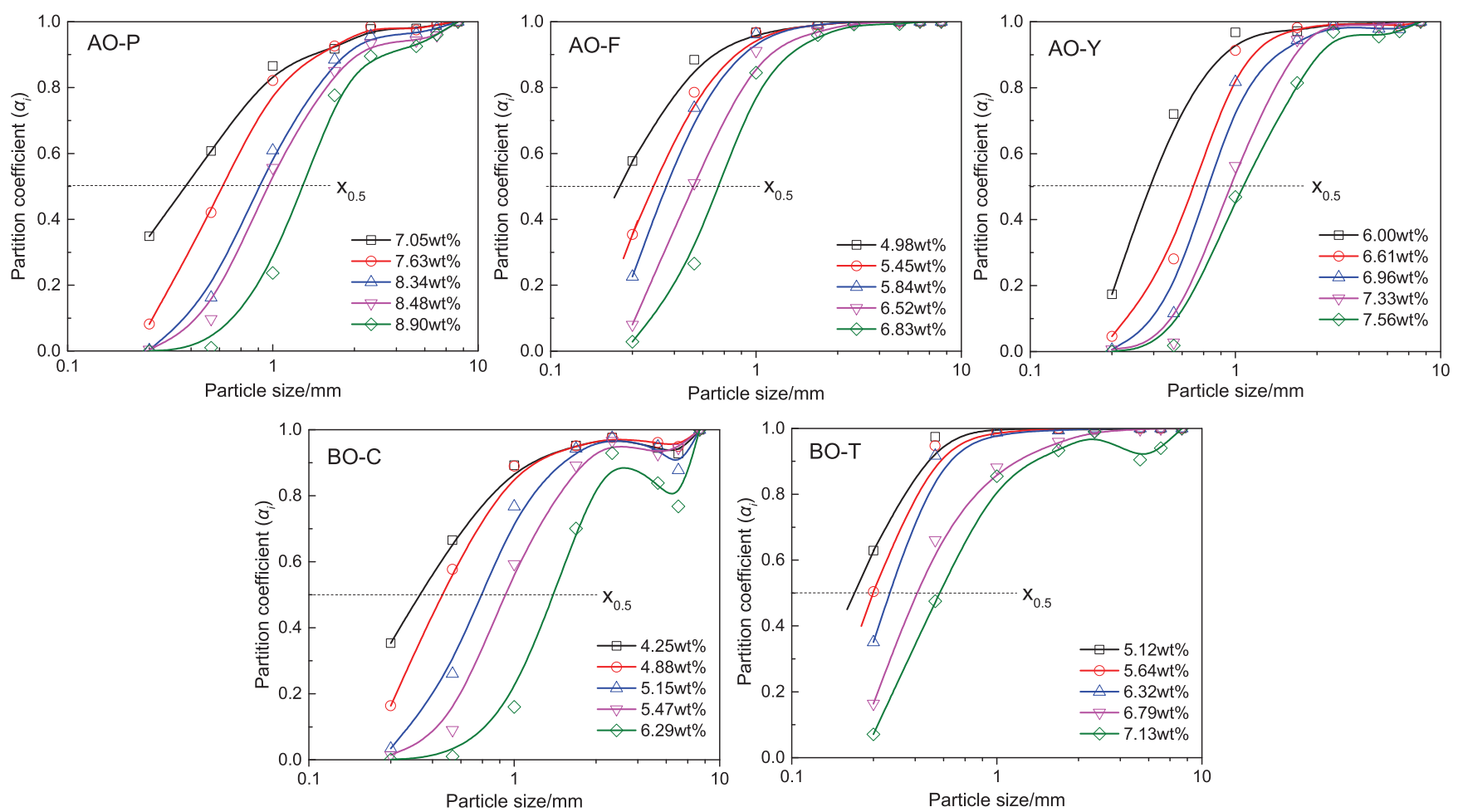

Fig. 2. Partition coefficient $\left(\alpha_{\mathrm{i}}\right) v s$. particle size curves for different ores. (Online version in color.)

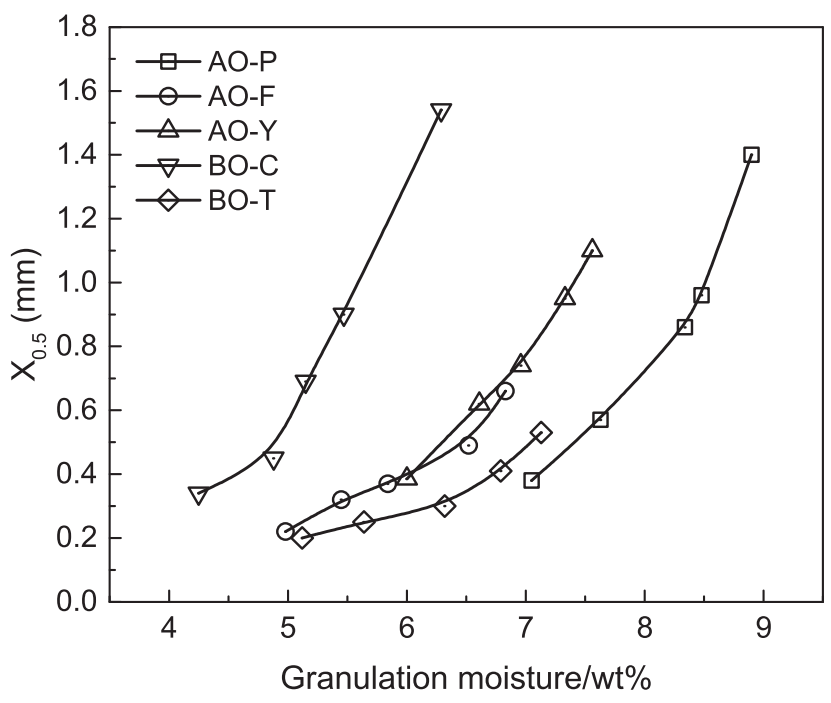

Fig. 3. Variation in $x_{0.5}$ with granulation moisture content for different ores.

into account.

Figure 4 shows the typical granule structure for five ores as well as mineralogical characteristics of the nucleus particles. Observationally, nucleus particles of AO-P, AO-Y and $\mathrm{BO}-\mathrm{C}$ generally show porous and rough appearance, which is believed to have positive effect on adhering of fine particles. While higher porosity usually gives better water absorption capacity, higher roughness supports more incorporation of larger particles in granules due to higher mechanical interlocking forces between ore particles. ${ }^{9,24)}$ On the contrary, AO-F and BO-T are less porous and mostly have smooth surface, which are closely related to their mineralogical characteristics. AO-F possesses considerable amount of vitreous goethite (bar-shaped and less porous) while BO-T possesses a high quantity of specular hematite (microplaty, dense and hard) and quartz. ${ }^{25)}$ Consequently, AO-P, AO-Y and BO-C have higher layer thickness and larger mean size of layering particles compared with AO-F and $\mathrm{BO}-\mathrm{T}$.

Figures 5(a)-5(e) typically shows the micrographs of layering particles in granules for different ores, and Fig. 5(f) shows the relationship between mass mean particle size and particle size of raw materials. Consistent with the mineralogical characteristics of nucleus particles, the layering particles of each ore exhibit distinct characteristics. While AO-P, AO-Y and BO-C are mostly granular particles, $\mathrm{AO}-\mathrm{F}$ and $\mathrm{BO}-\mathrm{T}$ appear platy. Round-shaped particles usually possess better granulating performance than flat ones. ${ }^{9)}$ Moreover, the mass mean particle size of fine fractions for different ores also shows a big difference: $\mathrm{BO}-\mathrm{T}$ has the smallest mean particle size while the other four ore types are relatively coarse and have a similar mean particle size of $-1 \mathrm{~mm}$ fraction. But the mean particle size of $-2 \mathrm{~mm}$ and $-3 \mathrm{~mm}$ fractions for AO-P, AO-F, $\mathrm{AO}-\mathrm{Y}$ and $\mathrm{BO}-\mathrm{C}$ turns to be quite different and follows the sequence: AO-F > AO-Y > AO-P > BO-C. Overall, from a qualitative view, the particle shape, the quantity and mean particle size of fine particles are all believed to have effect on the granulation effectiveness.

Quantitative study on the effects of ore characteristics was conducted based on the model as outlined in Section 2. The mean size of the particles in the adhering layer was postulated to be approximated to its mass mean size. Figure 6(a) shows a method for determination of mass mean size of layering particles from the size distributions of raw materials and mass fraction of layering particles. The latter is equivalent to the magnitude of volume fraction of layering particles $\left(V_{\mathrm{p}}\right)$, which can be calculated from Eq. (4). The volume fraction of layering particles for different ores is plotted against available moisture content $\left(W_{\mathrm{g}}\right)$, as shown 


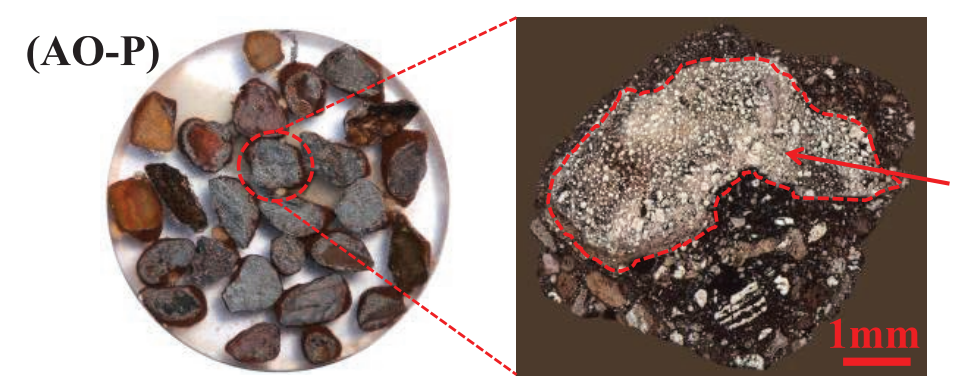

\section{Goethite-hematite \\ (porous and rough)}

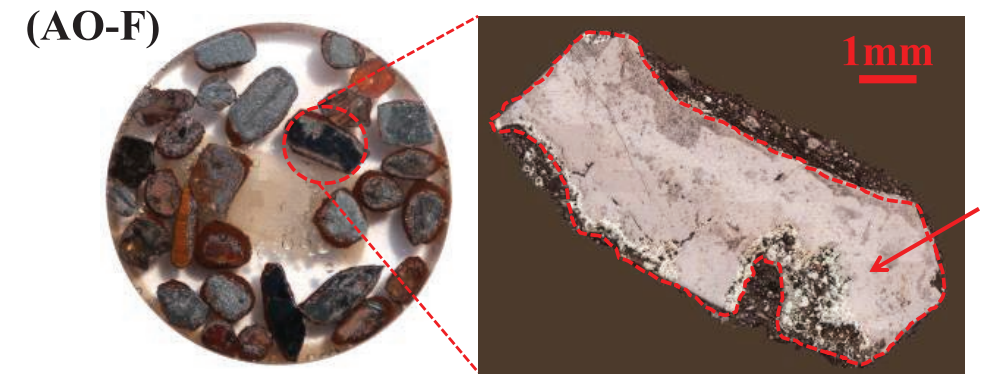

Vitreous goethite

(dense and smooth)

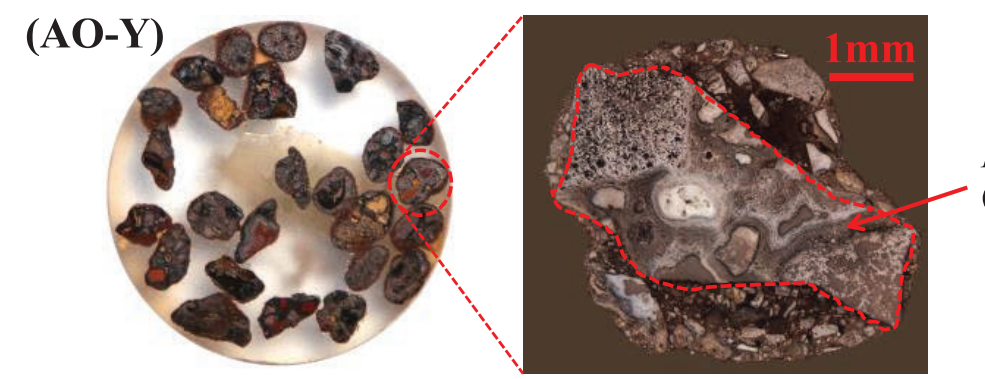

Pisolitic goethite

(porous and rough)

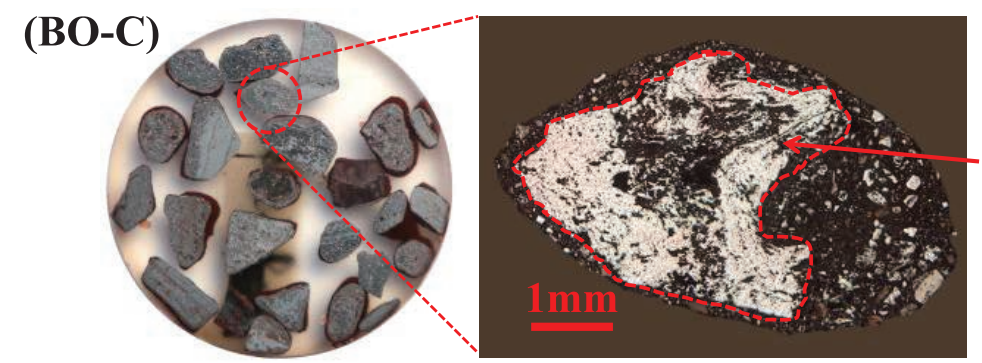

\section{Hematite}

(porous and rough)

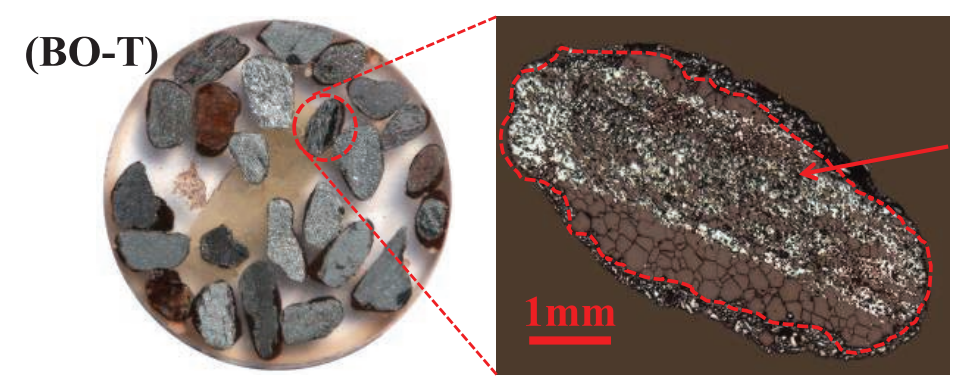

Microplaty specular hematite

and quartz

(dense and smooth)

Fig. 4. Typical $+5 \mathrm{~mm}$ granule structure for different ores $\left(x_{0.5}=0.5-0.7\right)$, showing the mineralogical characteristics of nucleus particles (identified as the dotted areas in the photos on the right side). (Online version in color.)

in Fig. 6(b). The volume fractions of layering particles for all ore types are found to have a linear relationship with available moisture content. This finding is significant as it implies the increasing rate of volume fraction of layering particles per unit available moisture content is constant, as expressed in Eq. (10).

$$
\frac{\Delta V_{p-1}}{\Delta W_{g}} \times 100 \%=\text { constant, } \% / \mathrm{kg} \mathrm{H}_{2} \mathrm{O} \cdot \mathrm{m}^{-3} \text { feed }
$$

Higher this value means higher layering rate of feed particles. The equation further confirms the proportionate layering mechanism that has been successfully used as a basis for modelling granulation process. ${ }^{17,26)}$ The constants for different ores are equivalent to the slopes of corresponding lines and they are: 0.502 for BO-C, 0.463 for BO-T, 0.377 for AO-P, 0.272 for AO-Y and 0.237 for AO-F. These values are found to have a roughly negative relationship with the mean size of raw materials as revealed in Fig. 5(f).

Since the porosity of adhering layer is assumed to be unchanged, the liquid saturation of adhering layer for each ore can be calculated from Eq. (3) and plotted against 
available moisture content, as shown in Fig. 6(c). The layer saturation varies widely with ore type: AO-P and BO-C (0.34-0.42), AO-Y (0.48-0.58), AO-F (0.70-0.77) and BO-T (0.56-0.97). The layer saturations for AO-P, AO-Y and $\mathrm{BO}-\mathrm{C}$ are found to increase slightly with moisture content. However, a slight decrease in layer saturation with increasing moisture content is observed for AO-F, while a sharp drop of layer saturation occurs for BO-T. The abnormality for the decrease of layer saturation with increasing moisture is attributed to the faster increase in volume frac-
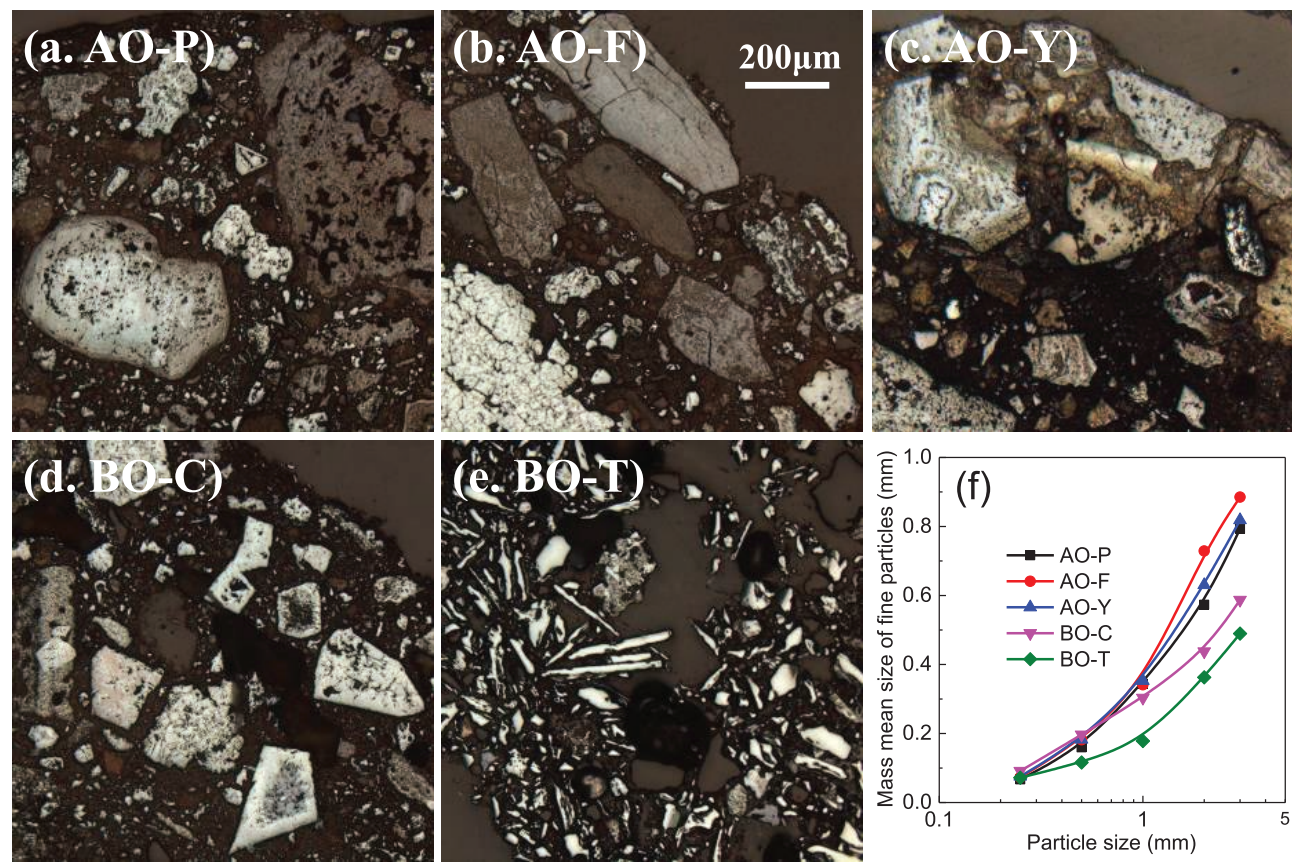

Fig. 5. Photomicrographs of layering particles in granules for different ores (a. AO-P; b. AO-F; c. AO-Y; d. BO-C; e $\mathrm{BO}-\mathrm{T}$ ); and (f) a plot of mass mean particle size $v s$. particle size of feeds (fine fraction). (Online version in color.)
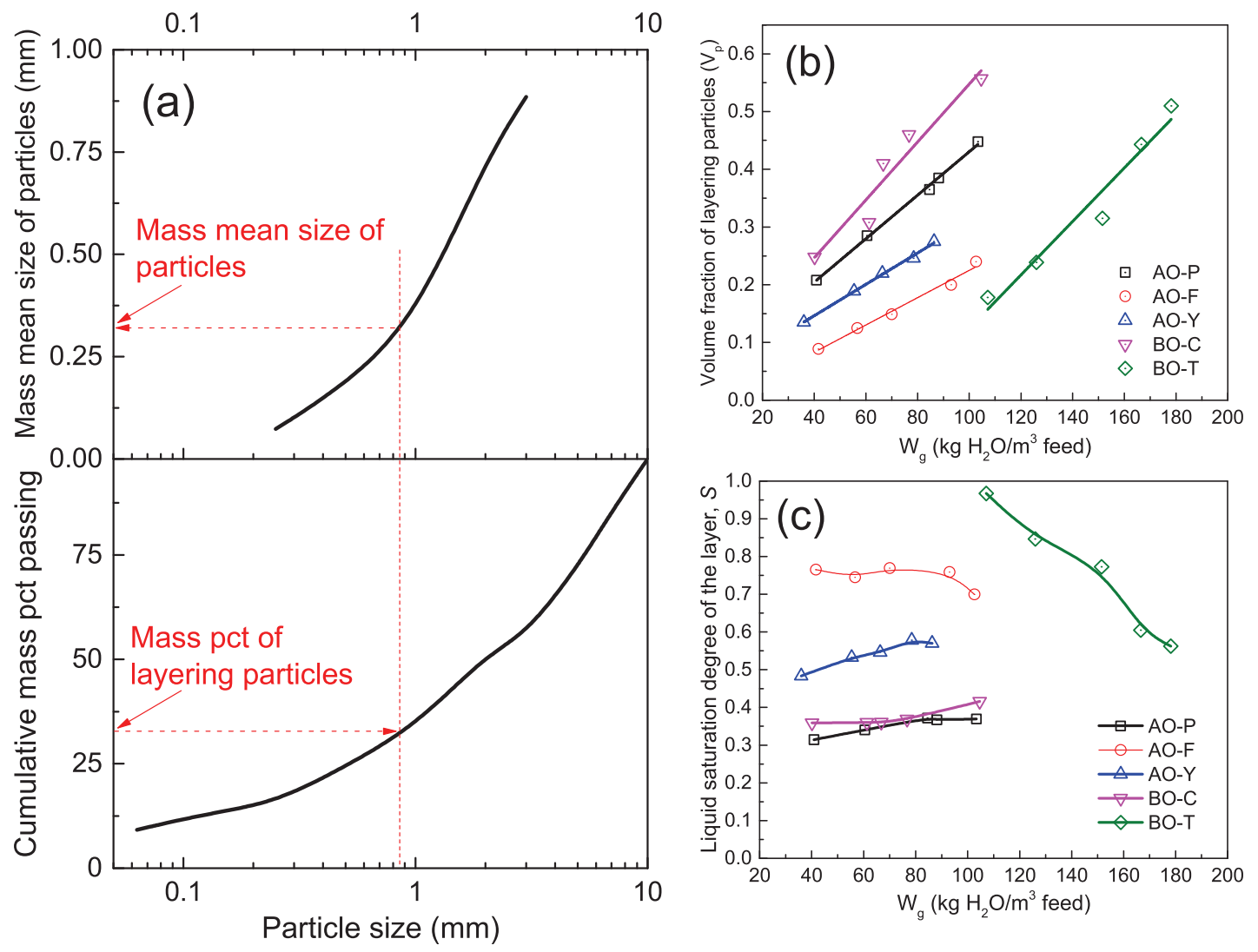

Fig. 6. (a) Determination of mass mean size of layering particles $\bar{d}$ from size distributions of raw materials and mass fraction of layering particles at a specific moisture content; (b) variation in volume fraction of layering particles $\left(V_{\mathrm{p}}\right)$ with available moisture content $\left(W_{\mathrm{g}}\right)$ for different ores; and (c) variation in layer saturation $(S)$ with available moisture content $\left(W_{\mathrm{g}}\right)$ for different ores. (Online version in color.) 
tion of layering particles $\left(V_{\mathrm{p}}\right)$ than moisture content $\left(W_{\mathrm{g}}\right)$ according to Eq. (3). For AO-F and BO-T, high liquid saturation at low moisture levels indicates that granules are in a pendular state when discrete lens-shaped rings are formed at the points of contact among ore particles. Noticeable growth of granules has yet to occur in this case when ore particles act more as nucleus particles. The above-mentioned properties of the adhering layer are summarized Table 3.

$(1-\varepsilon) S / \varepsilon \bar{d}$ in Eq. (2) can be considered as a feature parameter for layer binding strength $\sigma_{\mathrm{T}}$. Its values at various moisture contents for five ores are also calculated and provided in Table 3 . Increasing moisture content generally leads to a decrease in the value of $(1-\varepsilon) S / \varepsilon \bar{d}$ because of a significant increase in mean size of layering particles $\bar{d}$. This result also implies that the binding force at outer layer of a granule weakens with increasing large particles incorporated into the adhering layer until it can no longer withstand the separation forces to hold more particles. Conversely, a low moisture level generally gives a low mean particle size accounting for a high value of $(1-\varepsilon) S / \varepsilon \bar{d}$. While $(1-\varepsilon)$ $S / \varepsilon \bar{d}$ varies widely with moisture content and ore type, each ore exhibits its distinct potential to reach minimum of $(1-\varepsilon) S / \varepsilon \bar{d}$. Compared with AO-F and BO-T, AO-P, $\mathrm{AO}-\mathrm{Y}$ and $\mathrm{BO}-\mathrm{C}$ have obviously lower minimum values of $(1-\varepsilon) S / \varepsilon \bar{d}$.

To reveal the effect of ore properties and moisture content
Table 3. Properties of the adhering layer for different ores $^{\mathrm{c}}$.

\begin{tabular}{cccccc}
\hline Ores & $\begin{array}{c}W_{\mathrm{g}} \\
\left(\mathrm{kg} / \mathrm{m}^{3} \text { ore }\right)\end{array}$ & $\begin{array}{c}\text { Porosity of } \\
\text { the layer, } \varepsilon \\
(\%)\end{array}$ & $\bar{d}$ & $\begin{array}{c}\text { Liquid } \\
\text { saturation } \\
\text { of the } \\
\text { layer, } S\end{array}$ & $\left.\begin{array}{c}1-\varepsilon \\
\varepsilon\end{array}\right)$ \\
$\left(\mathrm{mm}^{-1}\right)$
\end{tabular}

c: The layer properties are provided only when the top size of layering particles reaches over $0.25 \mathrm{~mm}$.
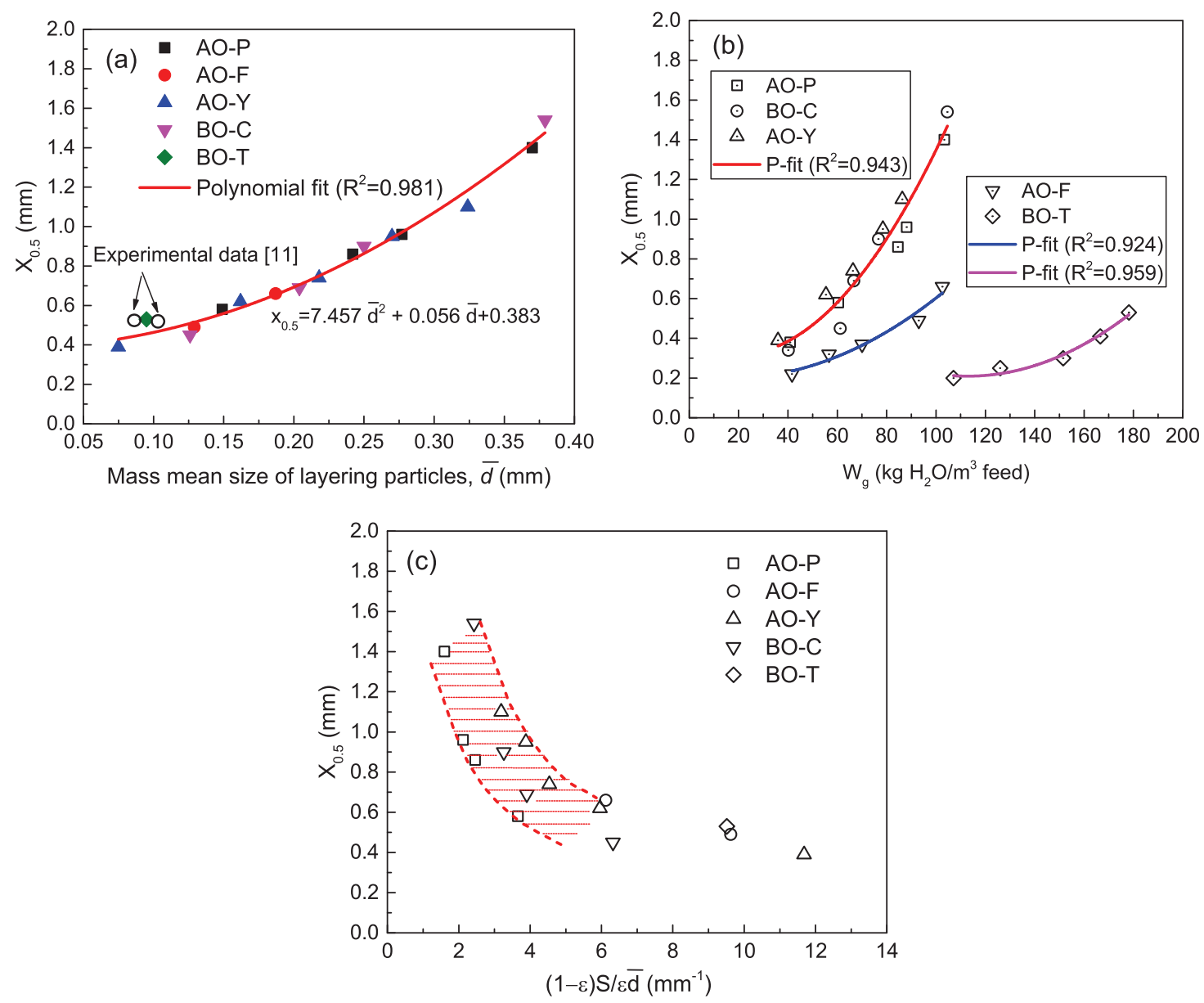

Fig. 7. (a) Normalized dependence of $x_{0.5}$ on mass mean size of layering particles; (b) normalized dependence of $x_{0.5}$ on available moisture content $\left(W_{\mathrm{g}}\right)$ for different ores; and (c) a plot of $x_{0.5}$ with $(1-\varepsilon) S / \varepsilon \bar{d}$ for different ores, and the shadow area shows effective values of $(1-\varepsilon) S / \varepsilon \bar{d}$ responsible for a successful normalization of $x_{0.5}$ with available moisture content. (Online version in color.) 
on the granulation effectiveness, the granulation effectiveness $x_{0.5}$ was fitted with mean size of layering particles $\bar{d}$ and available moisture content, as shown in Figs. 7(a) and 7(b), respectively. A single relationship independent of ore type between $x_{0.5}$ and mean size of layering particles $\bar{d}$ is achieved with little scatter. The results also show that simplified ore mixtures follow the same trend. This finding is significant as the relationship can be potentially applied to other ore types and more complex systems. Moreover, based on that, the granulation effectiveness of iron ore sinter feeds can be assessed using a simple and effective approach: measuring and comparing the mean size of layering particles at corresponding optimum moisture content.

When using available moisture content $\left(W_{\mathrm{g}}\right)$ as fitting parameter, $x_{0.5}$ for AO-P, AO-Y and BO-C can be normalized to be a single function of moisture content, similar to the previous finding. ${ }^{11)}$ However, both AO-F and BO-T can only achieve independent fittings, indicating that other factors besides the available moisture for granulation also play an important role in determination of granulation effectiveness. The large discrepancy of dependence of $x_{0.5}$ on available moisture content between AO-F, BO-T and other ores to a great extent is caused by their distinct particle size distributions. In the granulation process, the increase of mean granule size with time was ascribed to the role transition of some intermediate particles from nuclei to adhering particles and incorporation of small granules (intermediate particles as nuclei) into large granules. ${ }^{27)}$ The latter was a slower process which usually needed much longer time to complete than a given residence time for granulation. While AO-F possesses less layering particles than other ores, its higher proportion of intermediate particles $(-2.0$, $+0.5 \mathrm{~mm}: 26.60 \%$ ) makes it more difficult to coalesce with larger granules, hence resulting in a lower $x_{0.5}$ even at the same moisture content. Contrary to AO-F, BO-T has the highest proportion of fine particles $(-0.5 \mathrm{~mm}$ : $55.37 \%)$ with a smallest mean particle size, which is responsible for its low $x_{0.5}$. Furthermore, for a material with smaller particle size (BO-T), more water is required to give a high liquid saturation so that granules can start to grow after wetting and nucleation. ${ }^{28-30)}$ Substantial growth of granules appears when the granules consolidate and the water is squeezed to the granule surface. From this point, addition of a high amount of water has a potential to cause the granules of $\mathrm{BO}-\mathrm{T}$ to be plastic and deformable for consolidation. But on the other hand, it also presents an adverse effect on the permeability due to its high deformability. The above results further emphasize the importance of reasonable size distribution of feed mix to achieve desirable granulation effectiveness and packed bed permeability. ${ }^{31)}$

In addition, the results also raise a particular concern on the applicability of the model to the granulation process of AO-F and BO-T. Figure 7(c) shows the plot of $x_{0.5}$ with $(1-\varepsilon)$ $S / \varepsilon \bar{d}$ for different ores. Generally, $x_{0.5}$ is found to decrease with increase of $(1-\varepsilon) S / \varepsilon \bar{d}$. If taking $(1-\varepsilon) S / \varepsilon \bar{d}$ as a criteria, a successful normalization of $x_{0.5}$ with available moisture content can only be achieved when feed material possesses a high potential to reach a low value of $(1-\varepsilon) S / \varepsilon \bar{d}$ (minimum value $<3.2 \mathrm{~mm}^{-1}$ and most values $<6.0 \mathrm{~mm}^{-1}$ ). The proposed criteria are empirical and only applicable to the case of granulation process using water as a binder. Further verification of the criteria is necessary in future work by taking more types of sinter feeds into consideration.

\section{Conclusions}

In this study, conclusions are drawn as follows:

(1) Granulation effectiveness $x_{0.5}$ varies markedly with ore type and moisture content. Inherent size distribution of raw materials and moisture for granulation are manifested to be the paramount factors governing the granulation effectiveness.

(2) Granulation effectiveness $x_{0.5}$ is a strong function of mass mean size of layering particles independent of ore type. The mass mean size of layering particles is dependent on the inherent size distribution of the material and the mass fraction of layering particles. The latter has a linear dependence on available moisture content.

(3) While the J.D. Litster et al.'s model works well for some ore types, it fails to explain the observed relationship between $x_{0.5}$ and properties of those ores with unreasonable size distributions: excessive intermediate particles meanwhile lacking of fine particles; or excessive ultrafine particles. An criteria closely related to layer binding strength, $(1-\varepsilon) S / \varepsilon \bar{d}$, is proposed to determine the applicability of the model. Successful normalizations of $x_{0.5}$ with available moisture content can be achieved only at low values of $(1-\varepsilon) S / \varepsilon \bar{d}$ (minimum value $<3.2 \mathrm{~mm}^{-1}$ and most values $<6.0 \mathrm{~mm}^{-1}$ ).

\section{Acknowledgement}

Financial supports from the National Natural Science Foundation of China (No. 51574281), the National Torch Program of China (No. 2011GH561685) and Hunan Provincial Co-innovation Center for Clean and Efficient Utilization of Strategic Metal Mineral Resources are sincerely acknowledged. C. Yang is thankful to the China Scholarship Council (CSC) for financially supporting his $\mathrm{PhD}$ study in the Commonwealth Scientific and Industrial Research Organization (CSIRO), Brisbane, Australia. The authors also wish to thank other technical team members, Mengjie Xu, Xinqi Liu, Xincheng Yan, Shenghu Lu and Yue Shi, all master students with School of Minerals Processing and Bioengineering, Central South University, for their great assistance with the experiments of this work.

\section{Nomenclature}

$d$ : Mean size of layering particles, $\mathrm{mm}$

$\bar{d}$ : Mass mean size of layering particles, mm

$m_{i j}$ : Mass of particles of size fraction $i$ appearing in granules of size fraction $j, \mathrm{~kg}$

$M_{a-N}$ : Moisture absorbed by nucleus particles, $\mathrm{kg}$ water/ kg dry mass

$M_{a-A}$ : Moisture absorbed by adhering particles, $\mathrm{kg}$ water/kg dry mass

$S$ : Relative saturation of adhering layer in a granule

$V_{p}$ : Total volume fraction of layering particles

$w_{i}$ : Mass fraction of ore particles in size distribution $i$

$W_{T}$ : Total moisture added in the drum, $\mathrm{kg}$ water $/ \mathrm{m}^{3}$ dry ore

$W_{a}$ : Total moisture absorbed by feed materials, $\mathrm{kg}$ water $/ \mathrm{m}^{3}$ dry ore 
$W_{g}$ : Moisture available for the granulation, $\mathrm{kg}$ water/ $\mathrm{m}^{3}$ dry ore

$x_{0.5}$ : Cutoff size at which half of the particles act as nuclei particles and half act as adhering particles, $\mathrm{mm}$. This work defines the granulation effectiveness of iron ores as the magnitude of $x_{0.5}$.

$\alpha_{i}$ : Partition coefficient for size fraction $i$

$\varepsilon$ : Porosity of the adhering layer in a granule, $\%$

$\rho_{a}$ : Apparent density of feed material, $\mathrm{kg} / \mathrm{m}^{3}$

$\rho_{\mathrm{H}_{2} \mathrm{O}}$ : Density of water $\left(=1000 \mathrm{~kg} / \mathrm{m}^{3}\right)$

$\sigma_{\mathrm{T}}$ : Tensile strength of adhering layer in a granule, $\mathrm{N}$

\section{REFERENCES}

1) A. Formoso, A. Moro, G. Fernández Pello, J. L. Menéndez, M. Muniz and A. Cores: Ironmaking Steelmaking, 30 (2003), 447.

2) R. W. Roller: BHP Tech. Bull., 26 (1982), 44.

3) T. Furui, K. Sugawara, M. Kagawa, S. Uno, M. Kawazu, T. Fujiwara and A. Sawamura: Nippon Steel Tech. Rep. Overseas, 10 (1977), 36.

4) S. M. Iveson, J. D. Litster and B. J. Ennis: Powder Technol., 88 (1996), 15.

5) H. Zhou, M. X. Zhou, D. P. O'dea, B. G. Ellis, J. Z. Chen and M. Cheng: ISIJ Int., 56 (2016), 1920.

6) S. J. R. Simons, D. Rossetti, P. Pagliai, R. Ward and S. Fitzpatrick: Chem. Eng. Sci., 60 (2005), 4055.

7) L. M. Lu and O. Ishiyama: Iron Ore, ed. by L. M. Lu, Woodhead Publishing/Elsevier, Oxford, (2015), 395.

8) B. G. Ellis, C. E. Loo and D. Witchard: Ironmaking Steelmaking, 34 (2007), 99.

9) Y. Hida, K. Ito, J. Okazaki, M. Sasaki and Y. Umezu: Tetsu-toHagané, 68 (1982), 2166.

10) J. Khosa and J. R. Manuel: ISIJ Int., 47 (2007), 965.
11) J. D. Litster and A. G. Waters: Powder Technol., 55 (1988), 141.

12) X. W. Lv, X. B. Huang, J. Q. Yin and C. G. Bai: ISIJ Int., 51 (2011), 1432.

13) X. W. Lv, C. G. Bai, G. B. Qiu and M. L. Hu: Powder Technol., 204 (2010), 138.

14) X. B. Huang, X. W. Lv and Z. L. Xue: ISIJ Int., 56 (2016), 1964.

15) T. Higuchi, L. M. Lu and E. Kasai: ISIJ Int., 57 (2017), 1384.

16) C. C. Ekwebelam, B. G. Ellis and T. A. G. Langrish: Asia-Pac. J. Chem. Eng., 2 (2007), 137.

17) J. D. Litster, A. G. Waters and S. K. Nicol: Trans. Iron Steel Inst. Jpn., 26 (1986), 1036.

18) G. Z. Qiu, T. Jiang, X. H. Fan, D. Q. Zhu and Z. C. Huang: Scand. J. Metall., 33 (2004), 39.

19) J. S. Hall: Chem. Eng. Sci., 41 (1986), 187.

20) M. Yoshinaga, S. Sato and T. Kawaguchi: Australia/Japan Extractive Metallurgy Symp., AIMM, Sydney, (1980), 145.

21) W. J. Rankin, P. W. Roller and R. J. Batterham: Miner. Metall. Process., 278 (1985), 51.

22) J. Hinkley, A. G. Waters and J. D. Litster: Int. J. Miner. Process., 42 (1994), 37

23) J. Hinkley, A. G. Waters, D. O'Dea and J. D. Litster: Int. J. Miner. Process., 41 (1994), 53.

24) G. K. Reynolds, J. S. Fu, Y. S. Cheong, M. J. Hounslow and A. D. Salman: Chem. Eng. Sci., 60 (2005), 3969.

25) J. M. F. Clout and J. R. Manuel: Iron Ore, ed. by L. M. Lu, Woodhead Publishing/Elsevier, Oxford, (2015), 45.

26) R. Venkataramana, P. C. Kapur and S. S. Gupta: Chem. Eng. Sci., 57 (2002), 1685.

27) J. D. Litster and A. G. Waters: Powder Technol., 62 (1990), 125.

28) S. M. Iveson, J. D. Litster, K. Hapgood and B. J. Ennis: Powder Technol., 117 (2001), 3.

29) S. M. Iveson, P. A. Wauters, S. Forrest, J. D. Litster, G. M. Meesters and B. Scarlett: Powder Technol., 117 (2001), 83.

30) J. D. Litster: Powder Technol., 130 (2003), 35.

31) C. C. Yang, D. Q. Zhu, B. J. Shi, J. Pan, L. M. Lu, X. B. Li and Y. P. Mo: J. Iron Steel Res. Int., 24 (2017), 1007. 